\title{
Spatial Distribution and Seasonality of Halocline Structures in the Subarctic North Pacific
}

\author{
SHOTA KATSURA \\ Scripps Institution of Oceanography, University of California, San Diego, La Jolla, California \\ HIROMICHI UENO \\ Faculty of Fisheries Science, Hokkaido University, Hakodate, Japan \\ Humio Mitsudera \\ Institute of Low Temperature Science, Hokkaido University, Sapporo, Japan \\ SHINYA KOUKETSU \\ Japan Agency for Marine-Earth Science and Technology, Yokosuka, Japan
}

(Manuscript received 28 May 2019, in final form 22 October 2019)

\begin{abstract}
The spatial distribution and seasonality of halocline structures in the subarctic North Pacific (SNP) were investigated using Argo profiling float data and various surface flux data collected in 2003-17. The permanent halocline $(\mathrm{PH})$ showed zonal patterns in the spatial distributions of its depth and intensity and tended to be shallow and strong in the eastern SNP but deep and weak in the west. Mean distributions of PH depth and intensity corresponded to the winter mixed layer depth and sea surface salinity, respectively, indicating that it forms in association with the development of the winter mixed layer. In the Western Subarctic Gyre and Alaskan Gyre, where a relatively strong PH formed, $\mathrm{PH}$ intensity and depth showed clear seasonal variations, and deepening of the mixed layer compressed the underlying $\mathrm{PH}$ during the cooling period, resulting in intensification and development of the $\mathrm{PH}$ in late winter. In both regions, upwelling of high-salinity water also contributed to $\mathrm{PH}$ intensification. The summer seasonal halocline $(\mathrm{SH})$ showed distinct zonal differences in frequency and intensity, which were opposite to the PH distribution. While an SH formed in the western and central SNP and coastal regions, it was seldom present in the eastern area. This zonal contrast of SH corresponded to freshening of the mixed layer during the warming period, primarily reflecting freshwater flux. Geostrophic and Ekman advection play important roles in spatial differences in SH intensity and depth. SH development contributed to $\mathrm{PH}$ intensification in the following winter, by decreasing salinity above the $\mathrm{PH}$ through entrainment.
\end{abstract}

\section{Introduction}

The halocline is a region with a strong vertical salinity gradient, between an overlying low-salinity layer and an underlying high-salinity layer. When the halocline is the dominant contributor to density stratification and thus coincides with the pycnocline, vertical mixing across it is limited. In such cases, the halocline disrupts vertical heat transport, affecting the vertical temperature structure and hence also the sea surface temperature. In addition, the halocline controls the vertical distribution of

\footnotetext{
Corresponding author: Shota Katsura, skatsura@ucsd.edu
}

substances such as nutrients and limits their vertical exchange (Andreev et al. 2002). Thus, knowledge of the halocline structure is important for understanding not only air-sea interactions, but also biogeochemical processes.

Halocline structures have been studied mainly in tropical and polar regions. In the tropics, a shallow halocline forms near the sea surface due to heavy precipitation (Sprintall and Tomczak 1992) and tilting of the sea surface salinity (SSS) front (Cronin and McPhaden 2002; Katsura et al. 2015), which causes strong density stratification within the isothermal layer and underlying barrier layer (Godfrey and Lindstrom 1989; 
Lukas and Lindstrom 1991). The barrier layer acts as an impediment to thermal and kinetic energy transport into the ocean interior (Vialard and Delecluse 1998a), and thus plays an important role in air-sea interactions, such as those associated with El Niño-Southern Oscillation (Vialard and Delecluse 1998b; Maes and Belamari 2011) and tropical cyclones (Balaguru et al. 2012). Due to the importance of barrier layers, their properties, distribution, variability, and formation mechanism have been intensively investigated (e.g., Sprintall and McPhaden 1994; Sato et al. 2004, 2006; Mignot et al. 2009; Qu et al. 2014).

In the Arctic Ocean, where the contribution of salinity to water density is large due to the small thermal expansion coefficient at low temperatures, vertical stratification is mostly caused by variation in salinity. A sharp halocline forms the pycnocline between the fresh and cool surface layer, and the salty and warm subsurface layer, which are supplied by river runoff and inflow from the Atlantic, respectively. The halocline determines the distribution and persistence of sea ice, by obstructing vertical mixing and upward heat transport (Aagaard et al. 1981; Rudels et al. 1996) and causing ice-albedo feedback effects (Perovich et al. 2011). The halocline and its associated salinity stratification also affect biogeochemical processes in the Arctic Ocean, limiting upward nutrient supply and contact between bottom water and the atmosphere in shelf seas (Cai et al. 2010; Bates et al. 2013). For these reasons, halocline structures and related freshwater budgets in the Arctic Ocean have been studied intensively (Carmack et al. 2016).

In this study, we focus on the halocline structure in the subarctic North Pacific (SNP), north of $42^{\circ} \mathrm{N}$ (Favorite et al. 1976), which is dominated by the cyclonic subarctic gyre. Subsurface water within the subarctic gyre upwells due to Ekman suction. Because subsurface water in the SNP is rich in macro and micronutrients (Nishioka and Obata 2017), this upwelling leads to higher surface nutrient and biological productivity levels compared to subtropical regions. Subsurface water in the SNP is also rich in $\mathrm{CO}_{2}$, and its upwelling in the SNP affects the exchange of $\mathrm{CO}_{2}$ between the ocean and atmosphere by altering $\mathrm{pCO}_{2}$ in the ocean mixed layer (Takahashi et al. 1993). Reflecting the seasonality of upwelling, the SNP acts as a sink and a source of atmospheric $\mathrm{CO}_{2}$ in the summer and winter, respectively (Midorikawa et al. 2002).

In the SNP, salinity increases with depth (Kida et al. 2015) and dominates vertical stratification due to low temperature, as in the Arctic Ocean. Surface layer salinity in the SNP is lower than in other regions due to an excess of precipitation relative to evaporation, and a sharp halocline underlies the surface layer, shaping the pycnocline (Fig. 1). This structure causes a vertical temperature inversion with mesothermal (temperature maximum) and dichothermal (temperature minimum) layers (Uda 1963; Ueno and Yasuda 2000), which can affect sea surface temperature when they are entrained into the winter mixed layer (Wirts and Johnson 2005). The halocline also separates the subsurface layer, which is rich in nutrients and $\mathrm{CO}_{2}$, from the surface layer and limits vertical exchange between these layers (Andreev et al. 2002). Thus, the halocline structure in the SNP may be significant not only in climate change, but also in biological production and fisheries.

Previous studies of the halocline structure in the SNP have been limited to its western and eastern edges, where time series of hydrographic observations are available (Nagano et al. 2016; Pelland et al. 2016). Thus, SNP haloclines have been far less studied than those in tropical and polar regions; fundamental structure, distribution, and seasonality remain unknown despite their importance to climate variability and biogeochemical processes. Recent accumulation of Argo profiling float data has enabled expansive investigation of the halocline structure over the entire SNP. The purpose of the present study is to describe the spatial distribution and seasonality of the halocline in the SNP using Argo profiling float data. The results of the present study are expected to lay the foundation of future studies of climate variability and biogeochemical processes in the SNP. The data and methods used in the present study are described in section 2 . The spatial distribution of the halocline is examined, as are the formation processes of the permanent halocline ( $\mathrm{PH})$ and seasonal haloclines ( $\mathrm{SHs}$ ), in section 3. Maintenance of a strong PH in the eastern SNP, and the formation of SHs in coastal regions and the Bering Sea are further discussed in section 4 , as is the contribution of SHs to PH intensification. A summary of our findings is provided in section 5 .

\section{Data and methods}

\section{a. Data}

The salinity $S$ and temperature data used in this study were obtained from Argo profiles collected in the North Pacific during 2003-17, which were edited as outlined in Oka et al. (2007). The Argo profiles before and after March 2015 were obtained from the Argo Global Data Assembly Center (ftp://usgodae.org/pub/outgoing/argo; ftp://ftp.ifremer.fr/ifremer/argo) and Advanced automatic QC Argo data version 1.2. from Japan Agency for MarineEarth Science and Technology (http://www.jamstec.go.jp/ ARGO/argo_web/argo/?page_id=100\&lang=en), respectively. Each profile was vertically interpolated at a 1-dbar interval using the Akima spline method (Akima 1970). 
Salinity
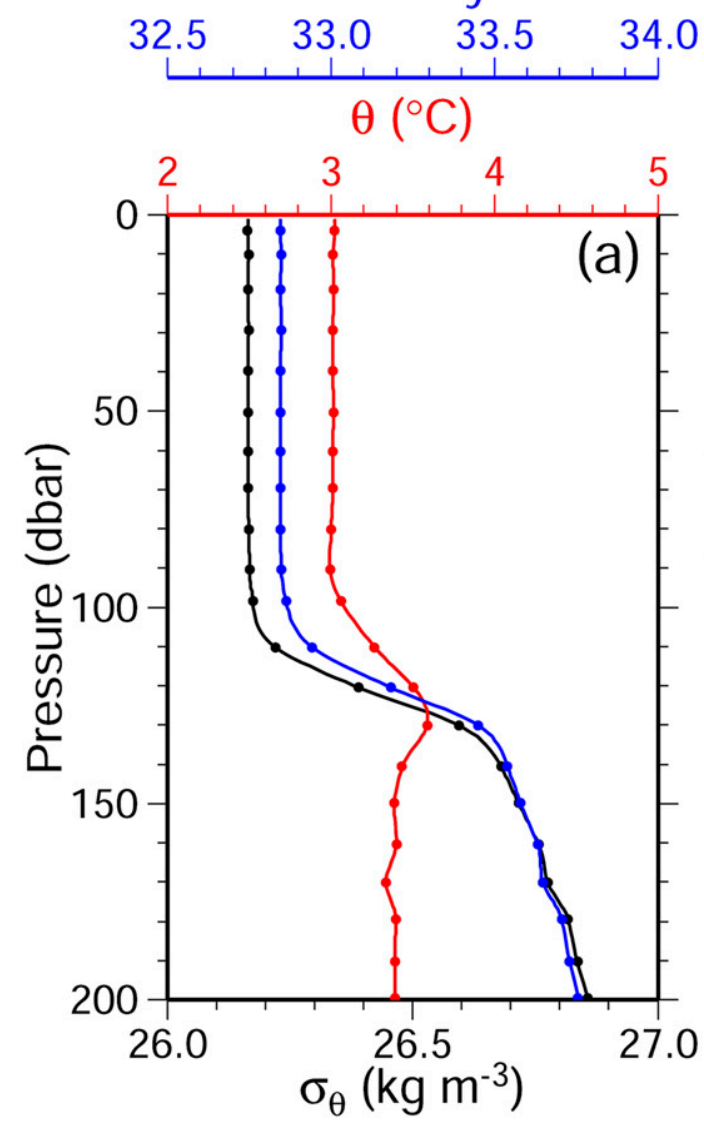

Salinity
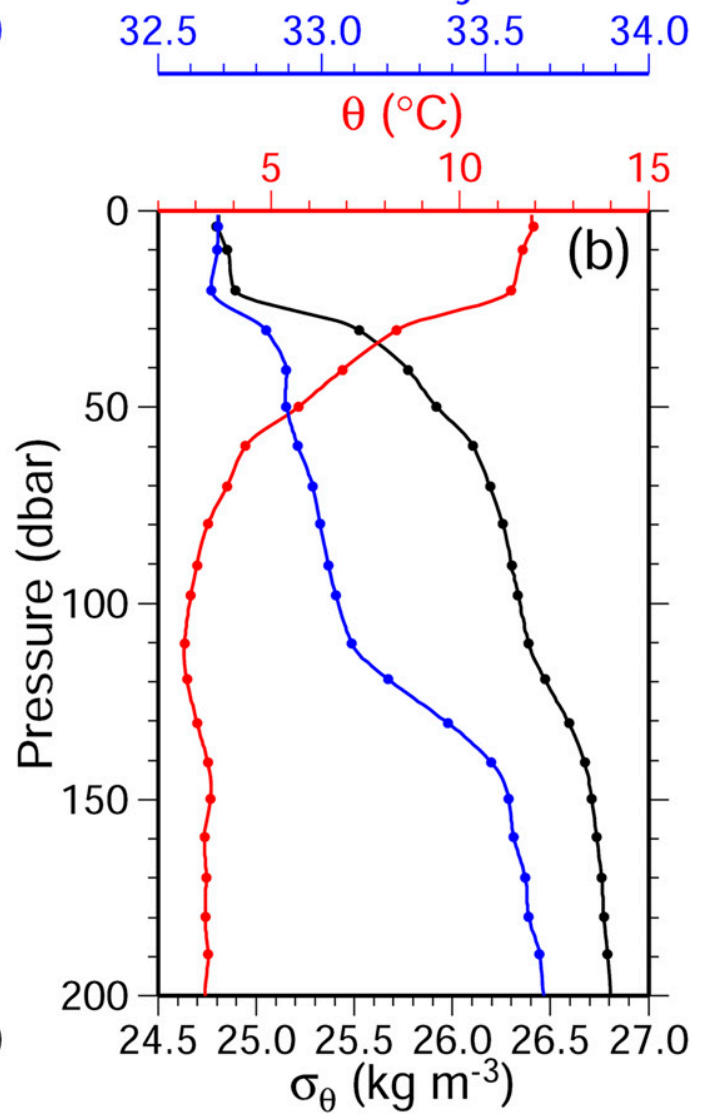

FIG. 1. Vertical profiles of salinity (blue), temperature (red), and $\sigma_{\theta}$ (black) observed with Argo float 2902496 at (a) $47.93^{\circ} \mathrm{N}, 175.46^{\circ} \mathrm{E}$ on $6 \mathrm{Feb} 2016$ and (b) $47.14^{\circ} \mathrm{N}, 179.00^{\circ} \mathrm{E}$ on $14 \mathrm{Aug} 2016$. Dots and lines indicate raw values and vertically interpolated values at an interval of 1 dbar obtained using the Akima spline (Akima 1970), respectively.

After interpolation, potential temperature $\theta$, potential density $\sigma_{\theta}$, and geopotential anomaly relative to 2000-dbar depth were calculated. Because some temperature and salinity profiles in the SNP showed their compensating contribution to density stratification (Fig. 2), both temperature and density criteria should be employed to determine the mixed layer depth (MLD) (Oka et al. 2007). The MLD was defined as the shallowest depth at which $\sigma_{\theta}$ is increased by $0.125 \mathrm{~kg} \mathrm{~m}^{-3}$ compared to 10-dbar depth, and the change in $\theta$ from 10 -dbar depth is equivalent to the $\sigma_{\theta}$ change in $\Delta \sigma_{\theta}=$ $0.125 \mathrm{~kg} \mathrm{~m}^{-3}$ at 10 -dbar salinity $S_{10}$, stated as

$$
\Delta \theta=\Delta \sigma_{\theta} /\left(\frac{\partial \sigma_{\theta}}{\partial \theta}\right)_{S_{10}} .
$$

We also used evaporation data from the Objectively Analyzed Air-Sea Heat Fluxes Project (OAFlux) (Yu and Weller 2007; Yu et al. 2008), precipitation data from the Climate Prediction Center Merged
Analysis of Precipitation (CMAP) (Xie and Arkin 1996, 1997), and wind stress data from the National Centers of Environmental Prediction (NCEP) (Kistler et al. 2001) collected in 2003-17. These data were linearly interpolated to $1^{\circ} \times 1^{\circ}$ horizontal resolution to correspond with the monthly climatological data described in the next subsection.

\section{b. Definition of haloclines and data gridding}

Some profiles showed multiple haloclines in association with intrusion of fresher and cooler water masses (Fig. 2). These haloclines did not coincide with the pycnocline due to density compensation caused by temperature. To describe the synoptic halocline structure in the SNP, we discarded profiles with downward salinity decreases greater than 0.2 for halocline detection. Note that such profiles were distributed mainly in the western boundary region of the SNP.

In this study, the halocline was defined in terms of the pressure $p$ derivative of salinity $\partial S / \partial p$, which was calculated 


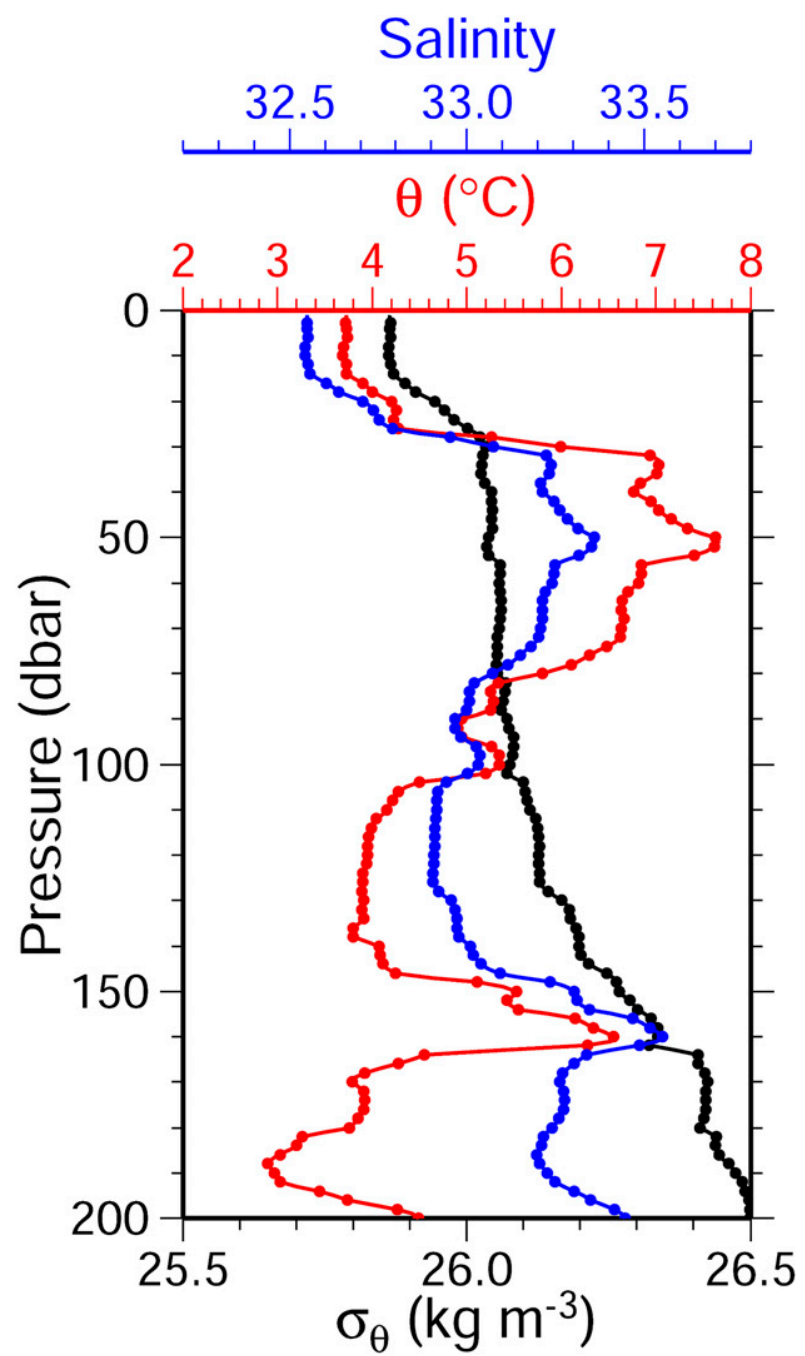

FIG. 2. Vertical profiles of salinity (blue), temperature (red), and $\sigma_{\theta}$ (black) observed with Argo float 5904033 at $42.05^{\circ} \mathrm{N}, 147.88^{\circ} \mathrm{E}$ on 5 Jan 2016. Dots and lines indicate raw values and vertically interpolated values at an interval of 1 dbar obtained using the Akima spline (Akima 1970), respectively.

using the least squares method in the range of $p \pm 5 \mathrm{dbar}$. More than 95\% of Argo profiles in the SNP during 2003-17 had vertical maximum values of $\partial S / \partial p$ greater than $1.0 \times 10^{-2} \mathrm{dbar}^{-1}$ (not shown). Based on this result, we defined the halocline as a vertical $\partial S / \partial p$ maximum greater than $1.0 \times 10^{-2} \mathrm{dbar}^{-1}$ and its intensity as the value of $\partial S / \partial p$ at that depth. In the SNP, a shallow SH usually forms in summer above the $\mathrm{PH}$, as indicated in Fig. 1b. To distinguish the $\mathrm{PH}$ from SHs, several profiles were investigated with respect to halocline depth (Fig. 3). While halocline depth was concentrated in a range greater than 70 dbar in winter (Fig. 3a), it had two peaks on either side of $70 \mathrm{dbar}$ in summer (Fig. 3b). Based on this result, we defined the $\mathrm{PH}$ as a halocline below $70 \mathrm{dbar}$ and the $\mathrm{SH}$ as a halocline above $70 \mathrm{dbar}$ in summer (July-September). When $\partial \theta / \partial p$ was positive at the depth of the $\mathrm{PH}$, we assumed it was associated with a temperature inversion.

The properties of haloclines and mixed layers and properties on isobaric and isopycnal levels were first estimated based on individual Argo profiles; then monthly climatological data of these properties were plotted with a resolution of $1^{\circ} \times 1^{\circ}$ in the SNP (north of $42^{\circ} \mathrm{N}$; Favorite et al. 1976) using a method similar to those of Oka et al. (2015) and Katsura (2018). First, temporary values of monthly climatological data were obtained for each grid point by averaging the values from the Argo profiles. These temporary values were averaged within a $3^{\circ}$ radius from the target grid point using a weighting function $d^{-2}$, where $d$ is the distance in degrees from the target grid point to the other grid points. During this process for halocline properties, Argo profiles without haloclines were not considered. This interpolation procedure was adopted to describe the distribution and seasonality of haloclines in greater detail preserving their properties to a greater extent than if we had estimate them based on horizontally interpolated temperature and salinity profiles.

\section{Results}

\section{a. Spatial distribution of permanent and seasonal haloclines}

The PH depth and intensity in the SNP showed spatial contrast in their distribution, especially in the zonal direction (Fig. 4). The PH was shallow in the eastern part of the SNP, with a horizontal minimum lower than $100 \mathrm{dbar}$ south of the Alaska Peninsula around $51^{\circ} \mathrm{N}$, $155^{\circ} \mathrm{W}$ (Fig. 4a). The $\mathrm{PH}$ deepened in the westward direction, and its depth exceeded 120 dbar in the western boundary region around $160^{\circ} \mathrm{E}$. The distribution of PH intensity also showed zonal contrast (Fig. 4b). While $\mathrm{PH}$ was strong in the eastern SNP, exceeding $3.0 \times$ $10^{-2} \mathrm{dbar}^{-1}$ east of $180^{\circ}$, it weakened westward and was less than $3.0 \times 10^{-2} \mathrm{dbar}^{-1}$ west of the international date line. A horizontal maximum PH intensity $(>4.0 \times$ $10^{-2} \mathrm{dbar}^{-1}$ ) was observed around $51^{\circ} \mathrm{N}, 155^{\circ} \mathrm{W}$, where $\mathrm{PH}$ was the shallowest. In the Bering Sea, $\mathrm{PH}$ was deeper than $120 \mathrm{dbar}$ and weaker than $2.0 \times 10^{-2} \mathrm{dbar}^{-1}$. Throughout the entire SNP, deeper PHs tended to be weaker, and shallower PHs tended to be stronger (spatial correlation coefficient $R=-0.67$ ).

$\mathrm{PH}$ showed similar depth and intensity distributions to winter MLD and SSS, respectively (Fig. 5). The winter mixed layer was shallow in the eastern SNP, with a depth of less than $100 \mathrm{dbar}$ east of $150^{\circ} \mathrm{W}$ (Fig. 5a). The shallow MLD extended westward along the Alaska Peninsula. 

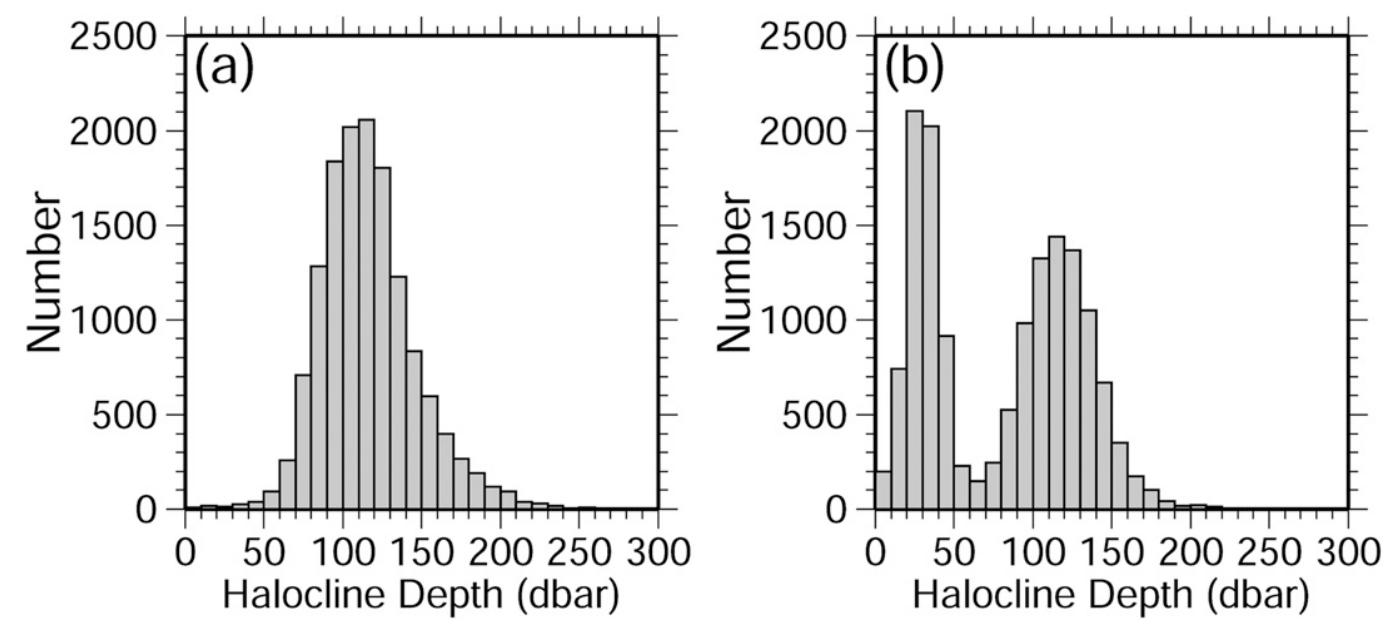

FIG. 3. Histogram of the number of Argo profiles north of $42^{\circ} \mathrm{N}$ in the North Pacific with respect to halocline depth in (a) January-March and (b) July-September of 2003-17.

The winter MLD exceeded 100 dbar west of $180^{\circ}$ and 120 dbar in the Bering Sea. These winter MLD distributions corresponded strongly to the distribution of PH depth (Fig. 4a; $R=0.85$ ). Winter SSS in the SNP also showed spatial variation, especially in the zonal direction (Fig. 5b). SSS was low in the eastern SNP, falling below 32.5 along the west coast of North America. The area of low SSS extended westward along $45^{\circ}-52^{\circ} \mathrm{N}$, increasing gradually. South of $45^{\circ} \mathrm{N}$ and in the Bering Sea, winter SSS exceeded 33.0. The SSS distribution was similar to that of the mean PH intensity (Fig. 4b), except for a horizontal SSS maximum centered at $53^{\circ} \mathrm{N}$, $150^{\circ} \mathrm{W}$, which indicated that $\mathrm{PH}$ tends to be stronger where SSS is lower but weaker where SSS is higher in the SNP $(R=-0.66)$. The correspondence of $\mathrm{PH}$ with winter MLD and SSS suggests that the PH forms in association with the development of the winter mixed layer, which is further explored in section $3 \mathrm{~b}$.

Temperature inversions were frequently observed when the PH was weak (Fig. 6). Temperature inversions were observed at a high frequency in the western part of the SNP $(>50 \%)$ and east of the Kamchatka Peninsula $(>70 \%)$, where $\mathrm{PH}$ was relatively weak. East of $180^{\circ}$, two bands with high frequencies of temperature inversion $(>50 \%)$ were observed; one extended southwestward from the Gulf of Alaska along the Aleutian Islands, and the other extended eastward to $135^{\circ} \mathrm{W}$ along $42^{\circ}-48^{\circ} \mathrm{N}$. At $48^{\circ}-52^{\circ} \mathrm{N}$, between those two bands, a PH with temperature inversion was detected in less than $20 \%$ of Argo profiles, although a PH intensity maximum was present in this region (Fig. 4b). In the Bering Sea, the temperature inversion frequency among Argo profiles was higher than 50\%, except north of the Aleutian Islands. This spatial distribution of temperature inversions in the SNP was consistent with the findings of previous studies (e.g., Ueno and Yasuda 2005), and temperature inversions were generally distributed where $\mathrm{PH}$ intensity was low.

The summer SHs were stronger and observed more frequently in the western part of the SNP than in the eastern part showing the opposite zonal pattern to the PH distribution (Fig. 7). In the eastern and central parts of the SNP $\left(165^{\circ} \mathrm{E}-155^{\circ} \mathrm{W}\right)$, summer SHs were observed in more than $70 \%$ of Argo profiles and had an average intensity of $2.0-3.0 \times 10^{-2} \mathrm{dbar}^{-1}$. SH frequency and intensity exceeded $90 \%$ and $3.0 \times 10^{-2} \mathrm{dbar}^{-1}$, respectively, in the western boundary region of the SNP and
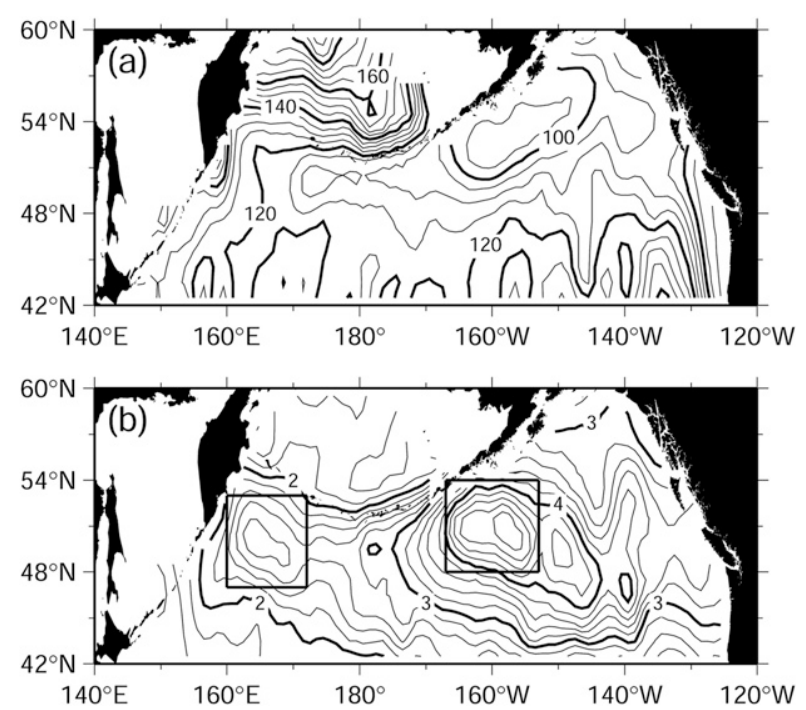

FIG. 4. Distribution of climatological annual mean (a) depth (dbar) and (b) $\partial S / \partial p\left(10^{-2} \mathrm{dbar}^{-1}\right)$ of the permanent halocline $(\mathrm{PH})$ in the subarctic North Pacific (SNP). Thick rectangles indicate the Western Subarctic Gyre (WSG) box $\left(47^{\circ}-53^{\circ} \mathrm{N}, 160^{\circ}-172^{\circ} \mathrm{E}\right)$ and Alaskan Gyre (AG) box $\left(48^{\circ}-54^{\circ} \mathrm{N}, 167^{\circ}-153^{\circ} \mathrm{W}\right)$. 

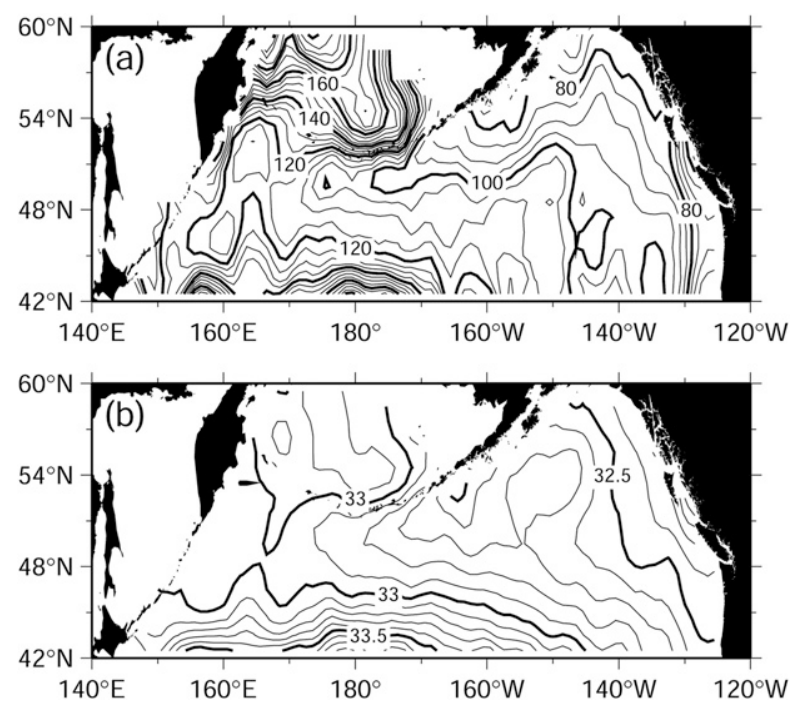

FIG. 5. Distribution of (a) the mixed layer depth (MLD; dbar) and (b) salinity at a depth of 10 dbar, averaged over January-March in the SNP.

the coastal region of North America. In the eastern part of the SNP $\left(42^{\circ}-54^{\circ} \mathrm{N}, 155^{\circ}-130^{\circ} \mathrm{W}\right), \mathrm{SH}$ frequency and intensity were lower than $40 \%$ and $2.0 \times 10^{-2} \mathrm{dbar}^{-1}$, respectively. In the Bering Sea, SH frequency was greater than $80 \%$ among Argo profiles in the western boundary and central $\left(180^{\circ}-150^{\circ} \mathrm{W}\right)$ regions. At $170^{\circ} \mathrm{E}-$ $175^{\circ} \mathrm{W}, \mathrm{SH}$ frequency was less than $50 \%$ and its intensity was below $2.0 \times 10^{-2} \mathrm{dbar}^{-1}$.

The zonal contrast of halocline structures in the SNP was apparent in the zonal section along $50^{\circ} \mathrm{N}$ in August (Fig. 8). The PH layer was found at 90-140 dbar east of $180^{\circ}$, and was associated with the pycnocline, with salinity and density ranges of 32.7-33.6 [practical salinity scale of 1978 (PSS-78)] and $\sigma_{\theta}=25.5-26.6 \mathrm{~kg} \mathrm{~m}^{-3}$, respectively, while both the salinity and $\sigma_{\theta}$ contours widened (and no PH was observed) west of $180^{\circ}$ (Figs. 8a,b). On the other hand, an SH was present around $30 \mathrm{dbar}$ at $155^{\circ} \mathrm{E}-160^{\circ} \mathrm{W}$ and corresponded to the MLD, while it was not found east of that area. Although no PH was present in the western part of the SNP, a temperature inversion occurred west of $170^{\circ} \mathrm{E}$ at $110-200 \mathrm{dbar}$, and was strongest at 110-160 dbar, with an intensity greater than $2.0 \times 10^{-2 \circ} \mathrm{C} \mathrm{dbar}^{-1}$ (Fig. $8 \mathrm{c}$ ).

\section{b. Development of a permanent halocline in the Western Subarctic Gyre and Alaskan Gyre}

As described in section 3a, a maximum of PH intensity $\left(>4.0 \times 10^{-2} \mathrm{dbar}^{-1}\right)$ was observed in the eastern part of the SNP around $51^{\circ} \mathrm{N}, 155^{\circ} \mathrm{W}$ (Fig. 4b). In the western $\mathrm{SNP}$, another maximum of PH intensity $(>2.8 \times$ $10^{-2} \mathrm{dbar}^{-1}$ ) was found around $50^{\circ} \mathrm{N}, 165^{\circ} \mathrm{E}$. These two maxima overlapped with the cyclonic Western Subarctic

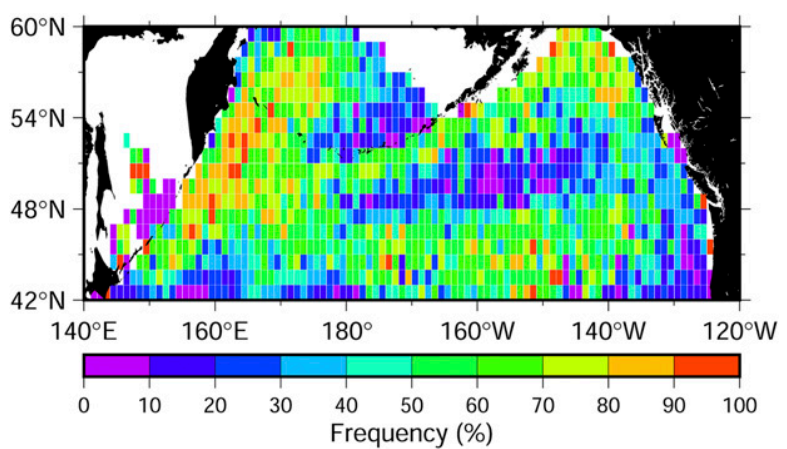

FIG. 6. Distribution of the frequency of Argo profiles in which the $\mathrm{PH}$ was associated with temperature inversions (\%), for the period $2003-17$ in the SNP.

Gyre (WSG) and Alaskan Gyre (AG), located at $45^{\circ}-54^{\circ} \mathrm{N}$, $155^{\circ}-175^{\circ} \mathrm{E}$ and $50^{\circ}-55^{\circ} \mathrm{N}, 165^{\circ}-145^{\circ} \mathrm{W}$, respectively (Fig. 9). To investigate the seasonal evolution of the $\mathrm{PH}$ in these two regions of maximum $\mathrm{PH}$ intensity, two grid boxes were selected (Figs. $4 \mathrm{~b}$ and 9 ): the WSG box $\left(47^{\circ}-53^{\circ} \mathrm{N}, 160^{\circ}-172^{\circ} \mathrm{E}\right)$ and the AG box $\left(48^{\circ}-54^{\circ} \mathrm{N}\right.$, $\left.167^{\circ}-153^{\circ} \mathrm{W}\right)$. In the WSG box, PH depths observed by Argo profiling floats were greatest in March, exceeding $125 \mathrm{dbar}$, and remained deep until October despite shoaling slightly (Fig. 10a). During this period, $\mathrm{PH}$ intensity decreased (Fig. 10c). PH depth decreased from October to November, corresponding to a reinforcement of the $\mathrm{PH}$ by the deepening and strengthening $\mathrm{SH}$, and then deepened until March due to compression by the deepening mixed layer. As the $\mathrm{PH}$ deepened, its intensity increased, reaching a seasonal maximum in February $\left(>4.0 \times 10^{-2} \mathrm{dbar}^{-1}\right)$. Both $\mathrm{PH}$ depth and intensity in the AG box showed similar seasonality to those in the WSG box (Figs. 10b,d). PH in the AG box exceeded $105 \mathrm{dbar}$ in March and remained deep during the warming period until October. PH then shoaled to 90 dbar in November and deepened during the cooling period until March, as did the mixed layer. $\mathrm{PH}$ in the AG box was strongest in February $\left(>6.0 \times 10^{-2} \mathrm{dbar}^{-1}\right)$ and weakened during warming period, whereas it intensified during the cooling period.

To further investigate the development of the $\mathrm{PH}$, we used a time series of vertical profiles obtained with Argo floats that stayed within the WSG and AG boxes (World Meteorological Organization IDs 4901563 and 4901561 , respectively) for more than 3 years (Fig. 9). Argo float 4901563 in the WSG box observed the seasonal development of the PH (Figs. 11a,b). The PH in WSG was around $120 \mathrm{dbar}$, with some fluctuations evident during the observation period. Above the $\mathrm{PH}$, an $\mathrm{SH}$ associated with the shallow mixed layer was formed at 20-30 dbar in summer around August, which then deepened from 

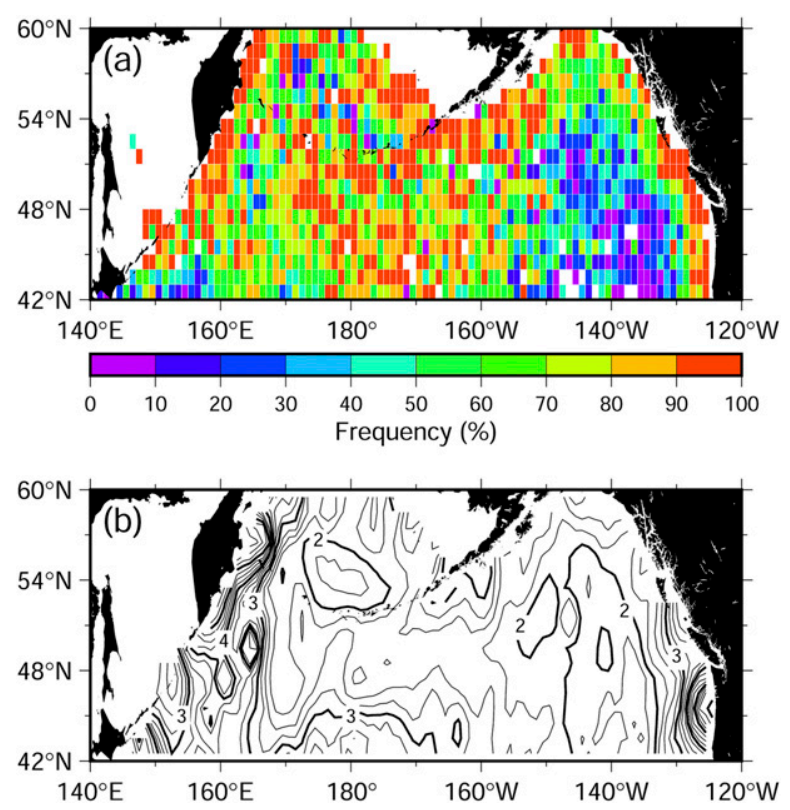

FIG. 7. (a) Distribution of the frequency of Argo profiles with seasonal haloclines (SH) (\%) in June-September in 2003-17, and (b) the $\partial S / \partial p\left(10^{-2} \mathrm{dbar}^{-1}\right)$ of SHs, averaged over June-September in the SNP.

autumn to winter. When this deepening mixed layer reached the underlying $\mathrm{PH}$, they combined to intensify the $\mathrm{PH}$. The depth of the temperature inversion in the WSG box corresponded well to the PH depth, and its intensity was not related to $\mathrm{PH}$ intensity or development (Fig. 11c). Similar seasonal development of the PH was found in the AG box (Figs. 12a,b). The PH in the AG box was detected by Argo float 4901561 around 90 dbar, which was shallower and stronger than that in the WSG box. As in the WSG box, an SH was formed at about 50 dbar around August, which then deepened during the cooling period to reach the underlying $\mathrm{PH}$, resulting in intensification of the $\mathrm{PH}$. In the AG box, no temperature inversion was present, as discussed in section $3 \mathrm{a}$, although the $\mathrm{PH}$ was stronger than that in the WSG box (Fig. 12c). Considering these results, the PH in the SNP forms in association with the development of the winter mixed layer and intensifies when compressed by deepening of the mixed layer.

To further investigate the formation of a stronger $\mathrm{PH}$ in the WSG and AG regions, we focused on the isohaline depth of 33.5 and isopycnal surface of $\sigma_{\theta}=26.5 \mathrm{~kg} \mathrm{~m}^{-3}$, which correspond to the PH depth in the SNP (Figs. 8, 11, and 12; Pelland et al. 2016). Acceleration potential on the isopycnal surface of $\sigma_{\theta}=26.5 \mathrm{~kg} \mathrm{~m}^{-3}$ relative to 2000-dbar depth and the depth of the 33.5 isohaline were estimated based on individual Argo profiles, and their monthly climatological data were then prepared following the procedure described in section $2 \mathrm{~b}$. On the isopycnal surface with $\sigma_{\theta}=26.5 \mathrm{~kg} \mathrm{~m}^{-3}$, stream lines reveal the WSG and AG (Fig. 13). In both gyres, the 33.5 isohaline surface was shallower than in surrounding regions, having depths of less than 140 and 120 dbar in the WSG and AG, respectively, indicating upwelling of high-salinity water in the subsurface of both gyres. This upwelled high-salinity water disrupts the deepening of the $\mathrm{PH}$ and compresses it, resulting in a stronger $\mathrm{PH}$ in the WSG and AG regions. The horizontal SSS maximum centered at $53^{\circ} \mathrm{N}, 150^{\circ} \mathrm{W}$ (Fig. $5 \mathrm{~b}$ ) may be a manifestation of this upwelling of high-salinity water.

\section{c. Formation of the seasonal halocline in summer}

As described in section 3a, the summer SH in the SNP showed a zonal contrast in terms of frequency of occurrence (Fig. 7a). To understand the factors influencing the spatial distribution of $\mathrm{SH}$, the following budget equation for mixed layer salinity (MLS) was used (Ren and Riser 2009; Katsura et al. 2013):

$$
\begin{aligned}
\frac{\partial S_{m}}{\partial t}= & \frac{(E-P) S_{m}}{h_{m}}-\mathbf{u}_{g} \cdot \nabla S_{m}-\mathbf{u}_{\mathrm{Ek}} \cdot \nabla S_{m} \\
& -w_{e} H\left(w_{e}\right) \frac{\Delta S_{m}}{h_{m}}
\end{aligned}
$$

where $S_{m}$ is MLS, $t$ is time, $E$ is evaporation, $P$ is precipitation, $h_{m}$ is MLD, $\mathbf{u}_{g}$ is geostrophic velocity, $\mathbf{u}_{\mathrm{Ek}}$ is Ekman velocity, $w_{e}$ is entrainment velocity through the mixed layer base, $\nabla$ is the horizontal differential operator, $\Delta S_{m}$ is the salinity difference between the mixed layer and the underlying subsurface layer 20 dbar below (former minus latter), and $H$ is the Heaviside step function,

$$
H(x)=\left\{\begin{array}{l}
1,(x \geq 0) \\
0,(x<0)
\end{array} .\right.
$$

The term on the left-hand side (LHS) represents the salinity tendency, while terms on the right-hand side (RHS) are effects of air-sea freshwater flux (evaporation and precipitation), geostrophic advection, Ekman advection, and entrainment.

Ekman velocity $\mathbf{u}_{\mathrm{Ek}}$ was estimated as

$$
\mathbf{u}_{\mathrm{Ek}}=\frac{1}{\rho_{0} f h_{m}}\left(\tau^{y},-\tau^{x}\right),
$$

where $\tau^{x}$ and $\tau^{y}$ are the zonal and meridional wind stresses (positive eastward and northward), $f$ is the Coriolis parameter, and $\rho_{0}$ is the reference density of seawater, $1025 \mathrm{~kg} \mathrm{~m}^{-3}$. Geostrophic velocity $\mathbf{u}_{g}$ was calculated from the geopotential anomaly at 10-dbar depth relative to that at 2000-dbar depth, assuming geostrophy. Entrainment velocity $w_{e}$ was estimated as 

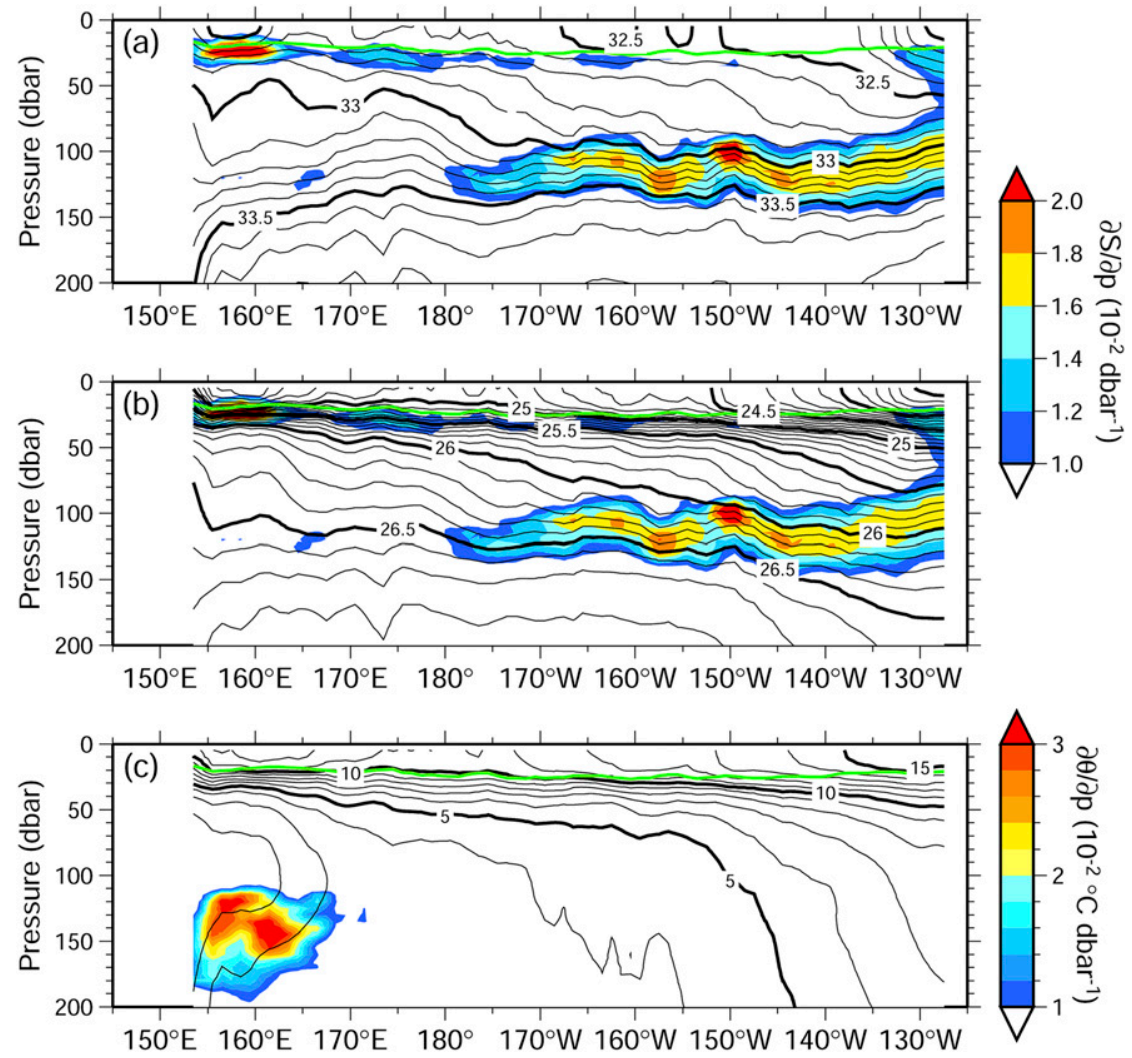

FIG. 8. The (a) salinity, (b) potential density $\left(\sigma_{\theta} ; \mathrm{kg} \mathrm{m}^{-3}\right)$, and (c) potential temperature $\left(\theta ;{ }^{\circ} \mathrm{C}\right)$ in the zonal section along $50^{\circ} \mathrm{N}$ in August (contours). Color indicates the $\partial S / \partial p$ in (a) and (b) and $\partial \theta / \partial p\left(>1.0 \times 10^{-2 \circ} \mathrm{Cdbar}^{-1}\right)$ in $(\mathrm{c})$. The green line indicates the MLD.

$$
\begin{aligned}
w_{e} & =w_{\mathrm{Ek}}+\left(\frac{\partial h_{m}}{\partial t}+\nabla \cdot h_{m} \mathbf{u}\right) \\
& =\frac{\nabla \times \tau}{\rho_{0} f}+\left(\frac{\partial h_{m}}{\partial t}+\nabla \cdot h_{m} \mathbf{u}\right),
\end{aligned}
$$

where $w_{\mathrm{Ek}}$ is Ekman vertical velocity generated by the convergence and divergence of the horizontal Ekman transport, and $\mathbf{u}$ is the sum of Ekman and geostrophic velocities (Yu 2011).

To evaluate the change in MLS from winter to summer, Eq. (2) was integrated from February to August:

$$
\begin{aligned}
S_{m}^{\mathrm{Aug}}-S_{m}^{\mathrm{Feb}}= & \int_{\mathrm{Feb}}^{\mathrm{Aug}}\left[\frac{(E-P) S_{m}}{h_{m}}-\mathbf{u}_{g} \cdot \nabla S_{m}-\mathbf{u}_{\mathrm{Ek}} \cdot \nabla S_{m}\right. \\
& \left.-w_{e} H\left(w_{e}\right) \frac{\Delta S_{m}}{h_{m}}\right] d t
\end{aligned}
$$

where the superscripts Aug and Feb indicate the values for February and August, respectively. Each term in Eq. (6) was calculated using monthly climatological data for the period 2003-17.

The distribution of MLS changes from winter to summer [LHS of Eq. (6)] corresponded well to the summer
SH distribution (Figs. $7 \mathrm{a}$ and $14 \mathrm{a}$ ). At $155^{\circ}-130^{\circ} \mathrm{W}$, where no summer SH was present, the MLS decrease was less than 0.2 , while it was greater than 0.2 in the western part of the SNP and along the coast of North America. The sum of the forcing terms on the RHS of Eq. (6) corresponded well with MLS changes and zonal differences,

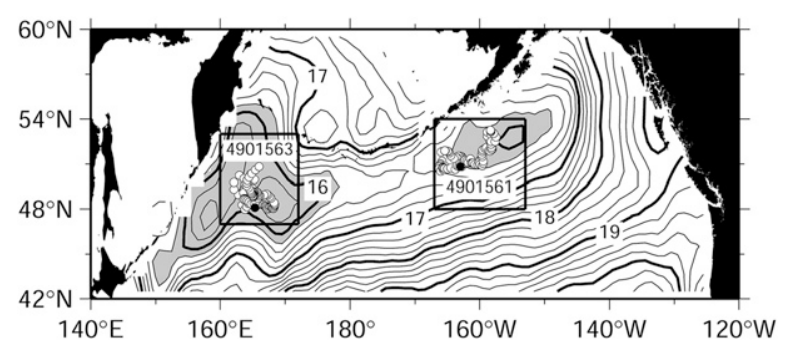

FIG. 9. Distribution of climatological annual mean geopotential anomaly $\left(\mathrm{m}^{2} \mathrm{~s}^{-2}\right)$ at a depth of 10 dbar relative to $2000 \mathrm{dbar}$ in the SNP (contour). Gray shading indicates values lower than $16.2 \mathrm{~m}^{2} \mathrm{~s}^{-2}$. White circles indicate the positions of vertical profiles observed with the Argo floats with World Meteorological Organization IDs 4901563 and 4901561, from July 2014 to June 2017 and from July 2013 to June 2016, respectively, and black circles indicate their initial positions during each period. Thick rectangles indicate the WSG box and AG box in Fig. 4b. 

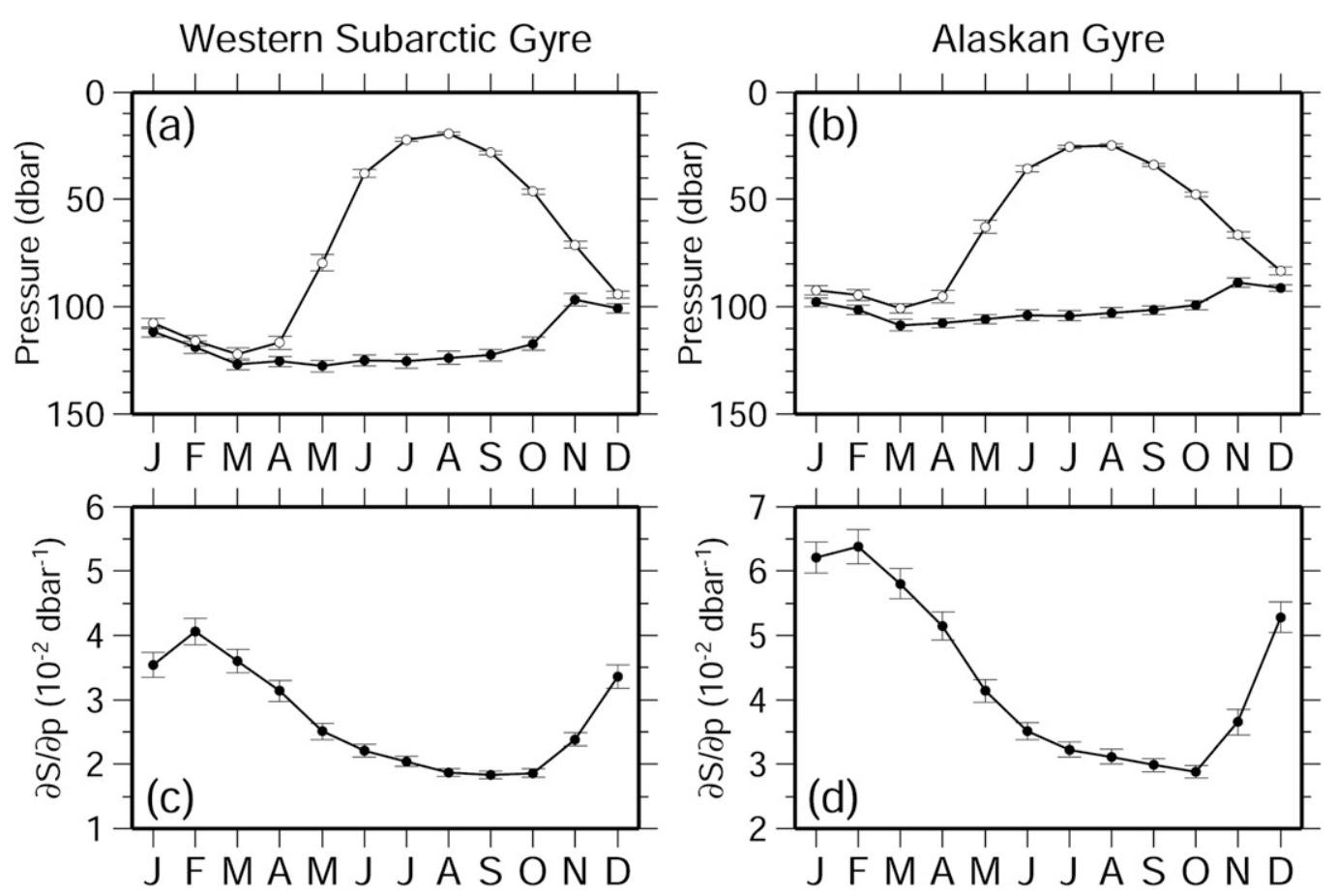

FIG. 10. Seasonal variations of (a),(b) the PH depth (black circle) and MLD (white circle) and (c),(d) $\partial S / \partial p$ $\left(10^{-2} \mathrm{dbar}^{-1}\right)$ of the PH based on raw Argo profiles, averaged over the period 2003-17 in the (left) WSG and (right) AG boxes. Vertical bars indicate the $95 \%$ confidence interval based on the standard deviation of Argo profiles over the 15 -yr period.

except along the North American coast and in the Bering Sea (Fig. 14b). This zonal difference of MLS change mainly reflected the freshwater flux term [first term on the RHS of Eq. (6); Fig. 14c]. Precipitation exceeded evaporation in the SNP; the MLS decrease due to freshwater flux was greater than 0.2 in the southwestern part of the SNP and along North America coast, while it was lower in the eastern part of the SNP, south of the Aleutian Islands, and in the Bering Sea. The geostrophic advection term [second term on the RHS of Eq. (6)] was positive throughout the SNP, except near the Aleutian Islands (Fig. 14d). Negative values near the Aleutian Islands compensated for small freshwater fluxes, aiding summer SH formation. The Ekman advection term [third term on the RHS of Eq. (6)] was negative for most of the SNP, as Ekman flow is directed southward due to westerly winds, leading to southward advection of fresher water (Figs. 14e,f). In the Gulf of Alaska, the Ekman advection term tended to be positive due to the local SSS maximum (Fig. 5b), and positive Ekman advection extended to the northern region without an $\mathrm{SH}$ around $51^{\circ} \mathrm{N}, 150^{\circ} \mathrm{W}$. Although the entrainment term [fourth term on the RHS of Eq. (6)] was positive and worked to increase MLS throughout the entire SNP, its magnitude was much smaller than those of the other terms $(<0.1$; not shown) because entrainment velocity $w_{\mathrm{e}}$ was dominated by mixed layer shoaling during this season [large negative value of $\partial h_{m} / \partial t$ in Eq. (5)]. Thus, the zonal contrast of SH can be explained by the MLS budget during the warming period, and the $\mathrm{SH}$ in the western region was formed by a combination of surface freshwater flux and geostrophic advection of fresher water near the Aleutian Islands. The absence of an $\mathrm{SH}$ in the eastern area was due to lower freshwater flux and Ekman advection of saltier water in the Gulf of Alaska.

\section{Discussion}

We found that the PH in the eastern SNP is shallower and stronger than that in the western part, and both the $\mathrm{PH}$ depth minimum and $\mathrm{PH}$ intensity maximum are found south of the Alaska Peninsula around $51^{\circ} \mathrm{N}$, $155^{\circ} \mathrm{W}$ (Fig. 4). However, their average positions did not correspond exactly, and an area of shallow $\mathrm{PH}$ was observed along the Alaska Peninsula, along with a more remote area of strong PH. In February, when PH was strongest (Figs. 10c,d), its intensity showed a horizontal maximum around $51^{\circ} \mathrm{N}, 160^{\circ} \mathrm{W}$, where it exceeded $6.0 \times 10^{-2} \mathrm{dbar}^{-1}$ (Fig. 15a). After formation, the $\mathrm{PH}$ weakened, probably due to mixing, and its maximum moved southeastward to around $49^{\circ} \mathrm{N}, 150^{\circ} \mathrm{W}$ 

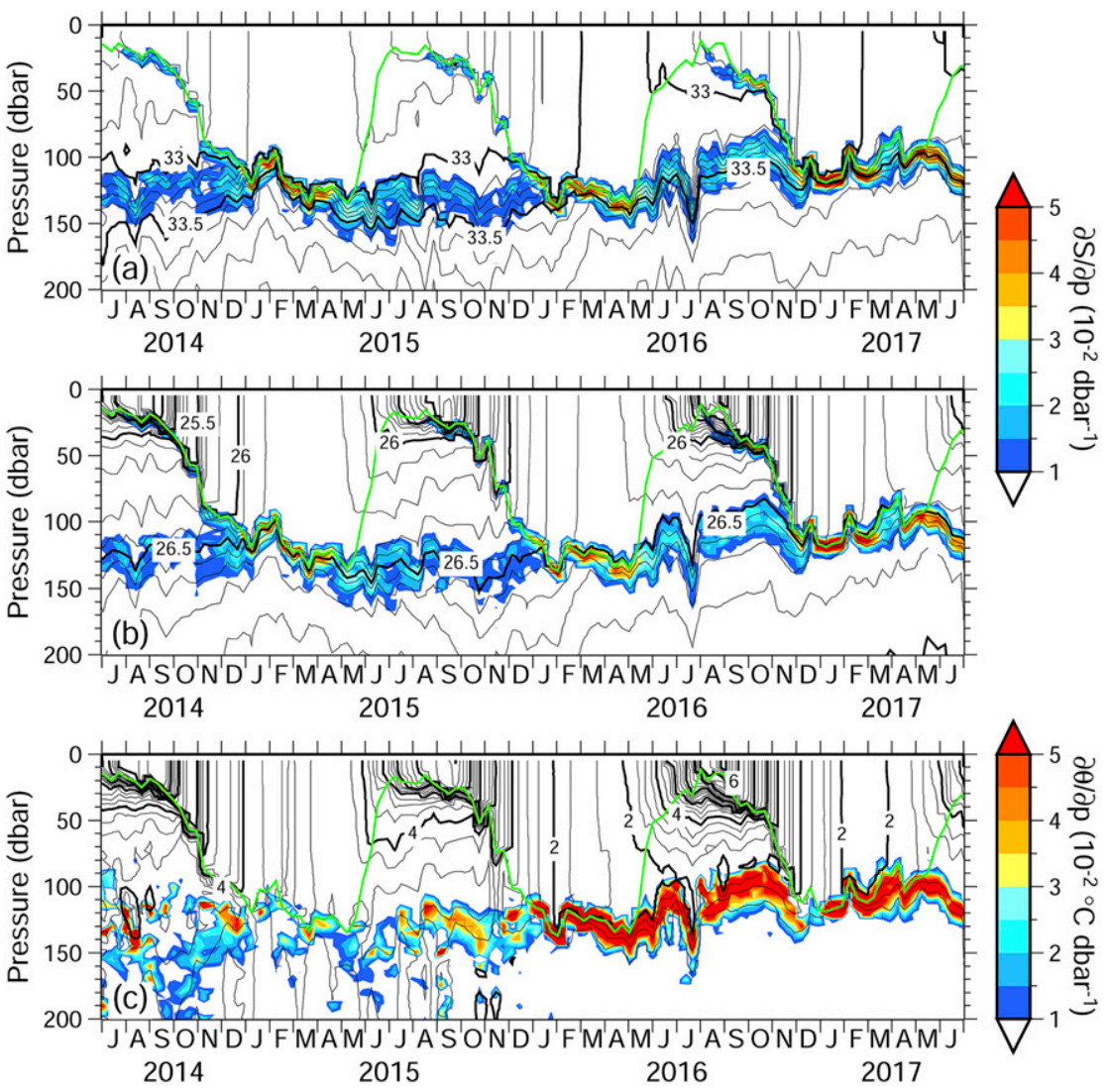

FIG. 11. Time series of vertical profiles of (a) salinity, (b) $\sigma_{\theta}\left(\mathrm{kg} \mathrm{m}^{-3}\right)$, and (c) $\theta\left({ }^{\circ} \mathrm{C}\right)$ observed with Argo float 4901563 from July 2014 to June 2017 (contour). Color indicates $\partial S / \partial p$ in (a) and (b) and $\partial \theta / \partial p .\left(>1.0 \times 10^{-2 \circ} \mathrm{Cdbar}^{-1}\right)$ in (c). The green line indicates the MLD.

during the warming period (Figs. 15b,c). In November, when the $\mathrm{PH}$ began to intensify, a maximum $\mathrm{PH}$ intensity exceeding $4.0 \times 10^{-2} \mathrm{dbar}^{-1}$ was seen in the AG region around $54^{\circ} \mathrm{N}, 160^{\circ} \mathrm{W}$ (Fig. $15 \mathrm{~d}$ ), which corresponded well to the annual mean minimum depth of the PH (Fig. 4a). These seasonal distributions of PH intensity suggested that dissimilarity between areas of strong and shallow $\mathrm{PH}$ is due to maintenance of a strong $\mathrm{PH}$ southeast of the AG during the warming period.

The maximum $\mathrm{PH}$ intensity was distributed in areas without temperature inversion (Figs. $4 \mathrm{~b}$ and 6 ); this is counterintuitive, as instability due to temperature inversion must be compensated by salinity, generally leading to a stronger $\mathrm{PH}$. This region was located between areas of cross-gyre flow of warm and salty water, which play an important role in the maintenance of mesothermal structures in the eastern SNP (Ueno and Yasuda 2000, 2001, 2003). The absence of warm, salty water advection may be essential for maintenance of the $\mathrm{PH}$ southeast of the AG, and this possibility should be further explored in future studies, as should the relationship of $\mathrm{PH}$ formation with the absence of temperature inversion.
The $\mathrm{PH}$ formed and intensified in winter due to compression by the winter mixed layer. When the winter mixed layer reached the $\mathrm{PH}$ and entrained the underlying saltier water, it intensified the $\mathrm{PH}$ and decreased the salinity above it (Fig. 16). To determine the spatial variations of this effect, we integrated the entrainment term in Eq. (2) (fourth term on the RHS) from August to February, that is, $\int_{\text {Aug }}^{\mathrm{Feb}}\left[-w_{e} H\left(w_{e}\right)\left(\Delta S_{m} / h_{m}\right)\right] d t$. The integrated entrainment term was positive throughout the entire SNP (Fig. 17), indicating that entrainment contributes to intensification of the PH in the SNP. The distribution of the integrated entrainment term values corresponded well to that of SH intensity (Fig. 7b). The effect of entrainment was greater where $\mathrm{SH}$ was stronger, and was smaller where SH was weaker, indicating that formation of the $\mathrm{SH}$ and associated freshening of the shallow mixed layer in summer affect intensification of the $\mathrm{PH}$ in the following winter, although the mean distribution of $\mathrm{PH}$ intensity primarily reflects gyre circulation.

We conducted an MLS budget analysis, described in section $3 \mathrm{c}$, to clarify the factors driving zonal differences in the $\mathrm{SH}$ distribution. The distribution of the 


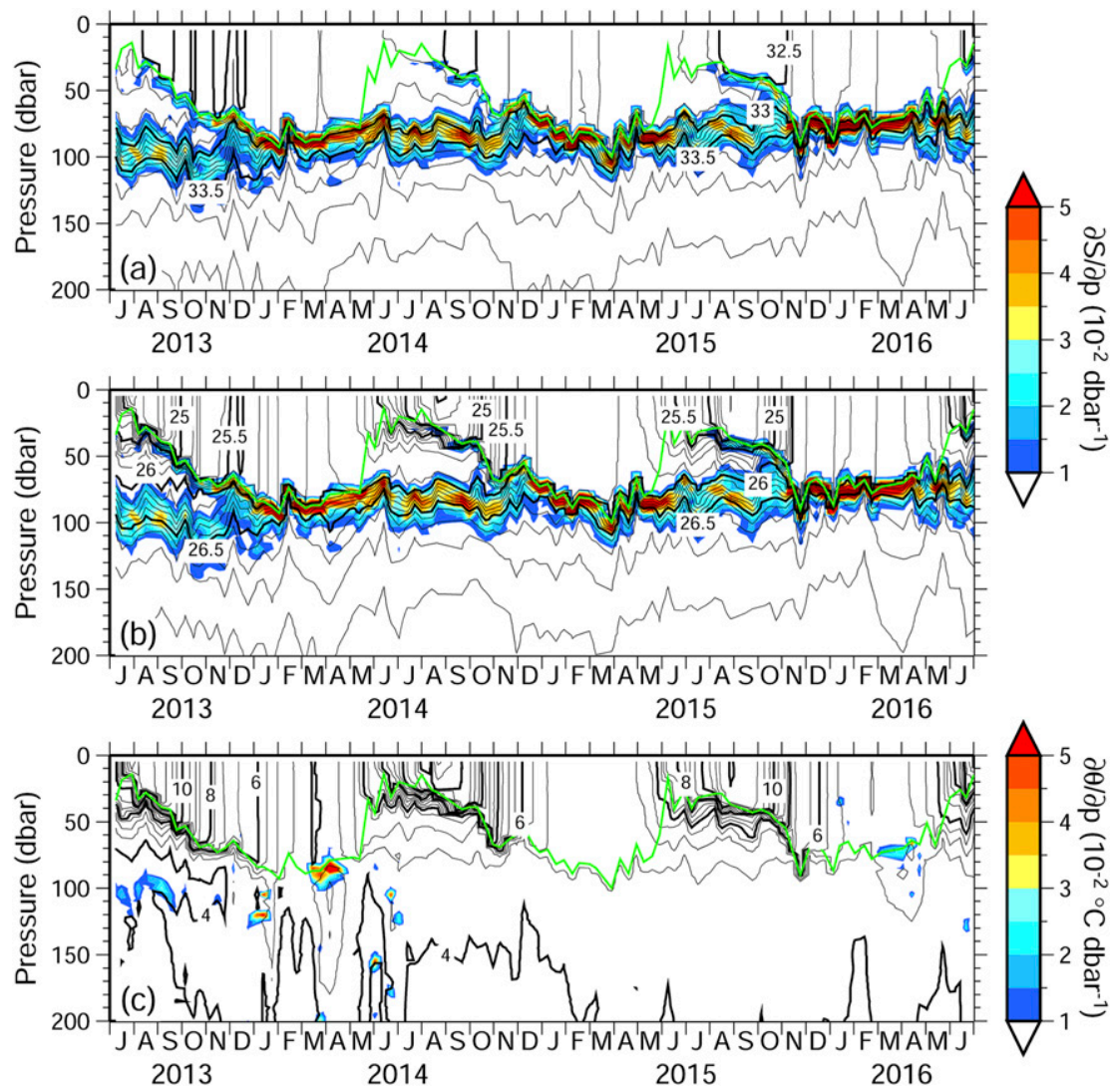

FIG. 12. As in Fig. 11, but showing profiles observed with Argo float 4901561 from July 2013 to June 2016.

integrated forcing terms during the warming period corresponded well to that of MLS changes, and the zonal contrast of SH in the SNP can be explained by a combination of freshwater flux, geostrophic advection, and Ekman advection (Figs. 14a,b). However, this budget is not closed along the coast of North America, in the western boundary region, or in the Bering Sea, where the decrease in the MLS during the warming period was underestimated. The imbalance of the MLS budget in these regions may be an effect of glacial and riverine runoff, which is not considered in Eq. (2). Freshwater input from rivers may play an important role in the formation of SHs in these areas. In the Bering Sea, melting sea ice may also be a driver of $\mathrm{SH}$ formation. In regional studies of $\mathrm{SH}$ in these areas, these effects should be considered.

We described the seasonal evolution of $\mathrm{SH}$ and $\mathrm{PH}$ in the SNP. SH in the SNP developed in summer near the sea surface in association with the shallow mixed layer. This seasonal evolution of $\mathrm{SH}$ is analogous to that of the seasonal thermocline in the subtropics which is caused by buoyancy flux in the surface layer associated with heat input during the warming period
(Price et al. 1986; Talley et al. 2011). This analogy between $\mathrm{SH}$ and the seasonal thermocline suggests that buoyancy acquired during the warming period is also important to $\mathrm{SH}$ formation, whereas $\mathrm{SH}$ intensity is determined by freshwater flux, as shown in section 3c. In the WSG and AG regions, where strong PHs were observed, $\mathrm{PH}$ was intensified through direct compression by the overlying winter mixed layer and upwelling of the underlying high-salinity water. This development of PH through vertical processes differs to that of the permanent thermocline in the subtropics; the upper part

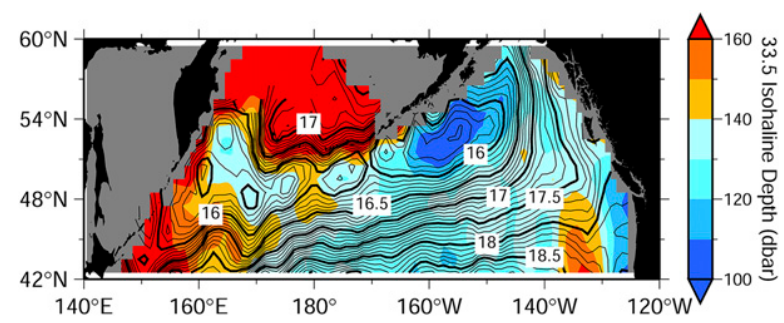

FIG. 13. Distribution of depth of the 33.5 isohaline (color; dbar) and acceleration potential at the isopycnal surface of $\sigma_{\theta}=26.5 \mathrm{~kg} \mathrm{~m}^{-3}$ (contour; $\mathrm{m}^{2} \mathrm{~s}^{-2}$ ), averaged over January-March in the SNP. 

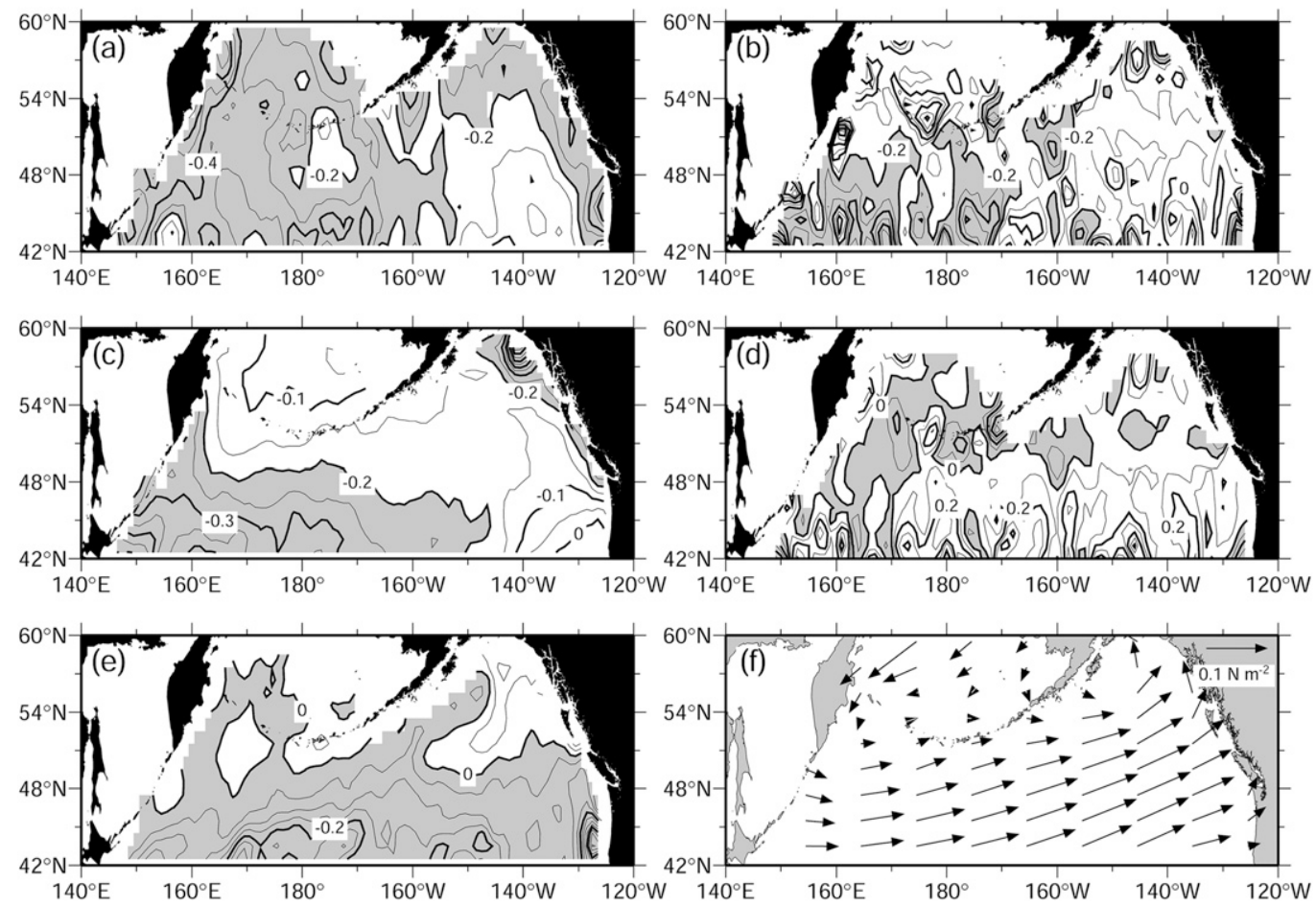

FIG. 14. Distribution of (a) MLS changes from February to August [left-hand side of Eq. (4)], (b) sum of the forcing terms, (c) freshwater flux term, (d) geostrophic advection term, and (e) Ekman advection term on the righthand side of Eq. (4) in the SNP. Gray shading indicates values lower than -0.2 in (a)-(c) and negative values in (d) and (e). (f) Distribution of mean wind stress during the period 2003-17 in the SNP.

of the permanent thermocline is ventilated, and subduction and horizontal advection along isopycnal surfaces play important roles in the development and maintenance of the permanent thermocline (Luyten et al. 1983). This contrast in development between the $\mathrm{PH}$ and the permanent thermocline suggests that
$\mathrm{PH}$ in the SNP is more sensitive to local surface forcing, especially in winter, than the subtropical permanent thermocline; therefore, local surface forcing affects temperature structure and biogeochemical processes through $\mathrm{PH}$ variation. The response and sensitivity of $\mathrm{PH}$ to surface forcing, as well as its relationship to
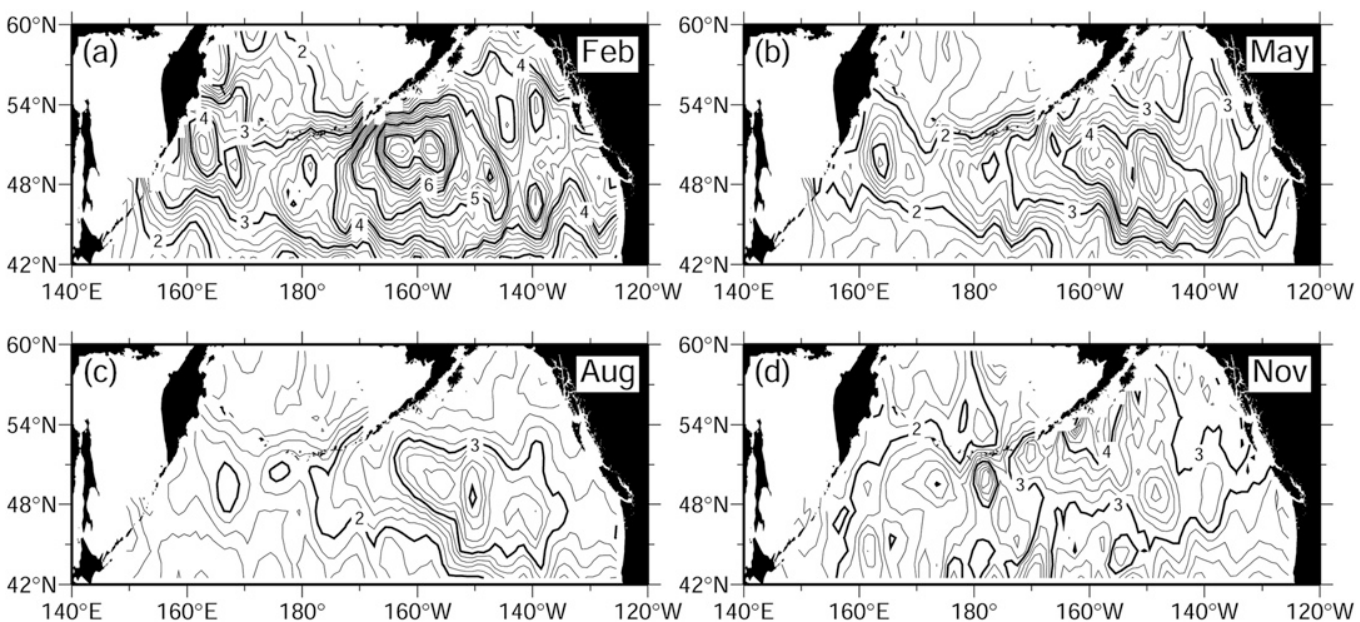

FIG. 15. Distribution of $\partial S / \partial p\left(10^{-2} \mathrm{dbar}^{-1}\right)$ of the PH in the SNP in (a) February, (b) May, (c) August, and

(d) November according to monthly climatological data. 


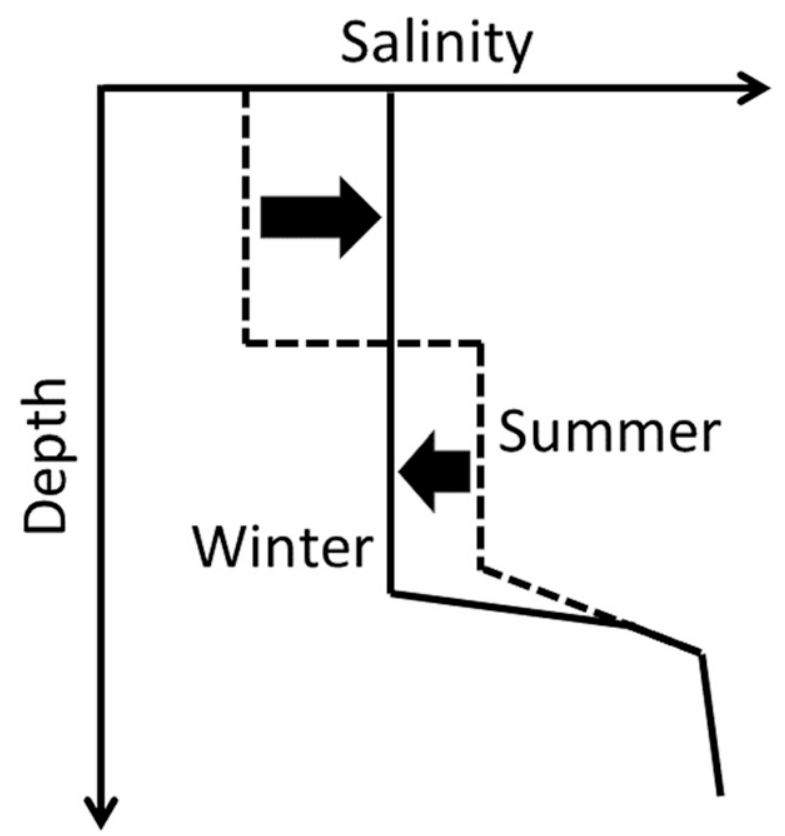

FIG. 16. Schematic diagram of PH intensification associated with entrainment. The solid and dashed lines indicate the vertical salinity profile in winter and summer, respectively.

temperature and biogeochemical parameters, will be further investigated in future research on interannual and decadal $\mathrm{PH}$ variation.

\section{Summary}

The spatial distribution and seasonality of halocline structures in the SNP were investigated using Argo profiling float data collected in the period 2003-17. The PH showed distinct zonal patterns in its depth and intensity distributions. A strong, shallow $\mathrm{PH}$ was found in the eastern SNP, with the strongest and shallowest $\mathrm{PH}$ located near the $\mathrm{AG}$ around $51^{\circ} \mathrm{N}, 155^{\circ} \mathrm{W}$, whereas the $\mathrm{PH}$ was weak and deep in the western SNP. The PH depth and intensity distributions corresponded to those of winter MLD and SSS, respectively, implying that the $\mathrm{PH}$ forms in association with winter mixing throughout the SNP. Temperature inversions were rarely associated with strong PH in the eastern SNP but they were observed where $\mathrm{PH}$ was relatively weak.

Two maxima of PH intensity occurred in the SNP, corresponding to the positions of the WSG and AG. In both regions, $\mathrm{PH}$ intensity and depth showed clear seasonal variations. $\mathrm{PH}$ remained shallow and weakened during the warming period. During the cooling period, the mixed layer containing the $\mathrm{SH}$ deepened and impinged upon the underlying $\mathrm{PH}$, resulting in intensification and development of the $\mathrm{PH}$ in late winter, and indicating that the formation of the $\mathrm{PH}$ occurs in

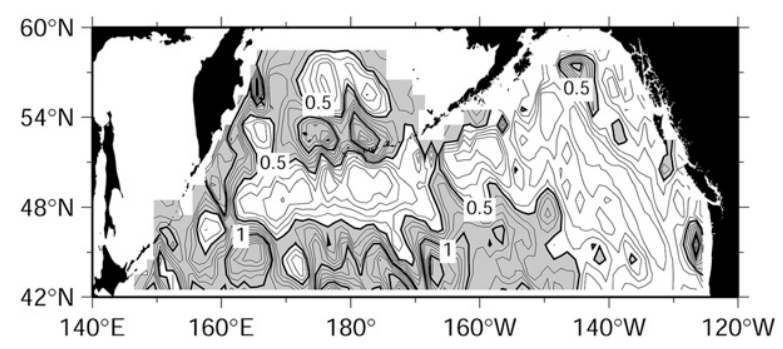

FIG. 17. Distribution of the integrated entrainment term from August to February in the SNP. Gray shading indicates values larger than 0.5 .

association with winter mixing. In the WSG and AG regions, high-salinity water in the subsurface was found at shallower depths than in surrounding areas due to upwelling within the two cyclonic gyres, which prevented the deepening of $\mathrm{PH}$, thus causing it to strengthen.

The summer SH also showed distinct zonal contrasts in terms of frequency and intensity. While an SH formed in the western and central SNP and coastal regions, it was seldom present in the eastern part of the SNP. This zonal pattern of SH corresponded well to that of freshening in the mixed layer during the warming period, mainly reflecting the freshwater flux effect. In some regions, the effects of geostrophic and Ekman advection were not negligible, and caused the zonal pattern of SH. Development of the summer SH also contributed to intensification of the $\mathrm{PH}$ due to entrainment during the following winter.

This study revealed the spatial distribution and seasonality of halocline structures in the SNP. As noted in section 1 , the halocline affects the vertical temperature structure, makes temperature inversions possible, and disrupts the vertical exchange of heat. Haloclines in the SNP also control the vertical distribution of biogeochemical parameters and limit vertical transport. These halocline effects may also vary regionally within the SNP, since halocline depth and intensity showed distinct spatial differences, especially in the zonal direction. The results of this study will provide a foundation for future investigations into the impact of spatiotemporal variation in haloclines on regional changes in temperature structure and biogeochemistry in the SNP, which will improve our understanding of the roles of oceans in air-sea interactions, climate variability, biological production, and fisheries.

Acknowledgments. The authors are thankful to Eitarou Oka, Takao Kawasaki, Yoshimasa Matsumura, Akira Nagano, and the participants of the "Research Meetings on Air-Sea Interaction," held in 2018 and 2017 as part of the Collaborative Research Program of the Hydrospheric Atmospheric Research Center, Nagoya University, and two anonymous reviewers for their 
valuable comments. SK is supported by JSPS Overseas Research Fellowships. The Argo float data used in this study were freely available from the International Argo Project and the national programs that contribute to it (http://www.argo.ucsd.edu; http://www.jcommops.org/ argo). Argo is a pilot program of the Global Ocean Observing System. This work was supported by JSPS KAKENHI Grant Numbers 17H01156 and 18K03736. The authors also thank Textcheck (www.textcheck.com) for English language editing.

\section{REFERENCES}

Aagaard, K., L. K. Coachman, and E. C. Carmack, 1981: On the halocline of the Arctic Ocean. Deep-Sea Res., 28, 529-545, https://doi.org/10.1016/0198-0149(81)90115-1.

Akima, H., 1970: A new method of interpolation and smooth curve fitting based on local procedures. J. Assoc. Comput. Mach., 17, 589-602, https://doi.org/10.1145/321607.321609.

Andreev, A., M. Kusakabe, M. Honda, A. Murata, and C. Saito, 2002: Vertical fluxes of nutrients and carbon through the halocline in the western subarctic gyre calculated by mass balance. Deep-Sea Res. II, 49, 5577-5593, https://doi.org/ 10.1016/S0967-0645(02)00200-X.

Balaguru, K., P. Chang, R. Saravanan, L. R. Leung, Z. Xu, M. Li, and J.-S. Hsieh, 2012: Ocean barrier layers' effect on tropical cyclone intensification. Proc. Natl. Acad. Sci. USA, 109, 14 343-14 347, https://doi.org/10.1073/pnas.1201364109.

Bates, N. R., M. I. Orchowska, R. Garley, and J. T. Mathis, 2013: Summertime calcium carbonate undersaturation in shelf waters of the western Arctic Ocean-How biological processes exacerbate the impact of ocean acidification. Biogeosciences, 10, 5281-5309, https://doi.org/10.5194/bg-10-5281-2013.

Cai, W. J., and Coauthors, 2010: Decrease in the $\mathrm{CO}_{2}$ uptake capacity in an ice-free Arctic Ocean basin. Science, 329, 556-559, https://doi.org/10.1126/science.1189338.

Carmack, E., and Coauthors, 2016: Freshwater and its role in the Arctic Marine System: Sources, disposition, storage, export, and physical and biogeochemical consequences in the Arctic and global oceans. J. Geophys. Res. Biogeosci., 121, 675-717, https://doi.org/10.1002/2015JG003140.

Cronin, M. F., and M. J. McPhaden, 2002: Barrier layer formation during westerly wind bursts. J. Geophys. Res., 107, 8020, https://doi.org/10.1029/2001JC001171.

Favorite, F., A. J. Dodimead, and K. Nasu, 1976: Oceanography of the subarctic Pacific region, 1960-71. International Commission Bulletin 13, 187 pp.

Godfrey, J. S., and E. J. Lindstrom, 1989: The heat budget of the equatorial western Pacific surface mixed layer. J. Geophys. Res., 94, 8007-8017, https://doi.org/10.1029/JC094iC06p08007.

Katsura, S., 2018: Properties, formation, and dissipation of the North Pacific Eastern Subtropical Mode Water and its impact on interannual spiciness anomalies. Prog. Oceanogr., 162, 120-131, https://doi.org/10.1016/j.pocean.2018.02.023.

, E. Oka, B. Qiu, and N. Schneider, 2013: Formation and subduction of North Pacific tropical water and their interannual variability. J. Phys. Oceanogr., 43, 2400-2415, https:// doi.org/10.1175/JPO-D-13-031.1.

, - _ and K. Sato, 2015: Formation mechanism of barrier layer in the subtropical Pacific. J. Phys. Oceanogr., 45, 27902805, https://doi.org/10.1175/JPO-D-15-0028.1.
Kida, S., and Coauthors, 2015: Oceanic fronts and jets around Japan: A review. J. Oceanogr., 71, 469-497, https://doi.org/ 10.1007/s10872-015-0283-7.

Kistler, R., and Coauthors, 2001: The NCEP-NCAR 50-Year Reanalysis: Monthly means CD-ROM and documentation. Bull. Amer. Meteor. Soc., 82, 247-267, https://doi.org/10.1175/ 1520-0477(2001)082<0247:TNNYRM $>2.3$.CO;2.

Lukas, R., and E. Lindstrom, 1991: The mixed layer of the western equatorial Pacific Ocean. J. Geophys. Res., 96, 3343-3357, https://doi.org/10.1029/90JC01951.

Luyten, J. R., J. Pedlosky, and H. Stommel, 1983: The ventilated thermocline. J. Phys. Oceanogr., 13, 292-309, https://doi.org/ 10.1175/1520-0485(1983)013<0292:TVT>2.0.CO;2.

Maes, C., and S. Belamari, 2011: On the impact of salinity barrier layer on the Pacific Ocean mean state and ENSO. SOLA, 7, 97-100, https://doi.org/10.2151/sola.2011-025.

Midorikawa, T., T. Umeda, N. Hiraishi, K. Ogawa, K. Nemoto, N. Kudo, and M. Ishii, 2002: Estimation of seasonal net community production and air-sea $\mathrm{CO}_{2}$ flux based on the carbon budget above the temperature minimum layer in the western subarctic North Pacific. Deep-Sea Res. I, 49, 339-362, https://doi.org/10.1016/S0967-0637(01)00054-1.

Mignot, J., C. de Boyer Montégut, and M. Tomczak, 2009: On the porosity of barrier layers. Ocean Sci., 5, 379-387, https:// doi.org/10.5194/os-5-379-2009.

Nagano, A., M. Wakita, and S. Watanabe, 2016: Dichothermal layer deepening in relation with halocline depth change associated with northward shrinkage of North Pacific western subarctic gyre in early 2000s. Ocean Dyn., 66, 163-172, https:// doi.org/10.1007/s10236-015-0917-8.

Nishioka, J., and H. Obata, 2017: Dissolved iron distribution in the western and central subarctic Pacific: HNLC water formation and biogeochemical processes. Limnol. Oceanogr., 62, 2004 2022, https://doi.org/10.1002/lno.10548.

Oka, E., T. Suga, and L. D. Talley, 2007: Temporal variability of winter mixed layer in the mid- to high-latitude North Pacific. J. Oceanogr., 63, 293-307, https://doi.org/10.1007/s10872-007-0029-2.

_ - and Coauthors, 2015: Decadal variability of subtropical mode water subduction and its impact on biogeochemistry. J. Oceanogr., 71, 389-400, https://doi.org/10.1007/s10872-015-0300-x.

Pelland, N. A., C. C. Eriksen, and M. F. Cronin, 2016: Seaglider surveys at Ocean Station Papa: Circulation and water mass properties in a meander of the North Pacific current. J. Geophys. Res. Oceans, 121, 6816-6846, https://doi.org/ 10.1002/2016JC011920.

Perovich, D. K., and Coauthors, 2011: Arctic sea-ice melt in 2008 and the role of solar heating. Ann. Glaciol., 52, 355-359, https://doi.org/10.3189/172756411795931714.

Price, J. F., R. A. Weller, and R. Pinkel, 1986: Diurnal cycling: Observations and models of the upper ocean response to diurnal heating, cooling, and wind mixing. J. Geophys. Res., 91 , 8411-8427, https://doi.org/10.1029/JC091iC07p08411.

Qu, T., T. Song, and C. Maes, 2014: Sea surface salinity and barrier layer variability in the equatorial pacific as seen from Aquarius and Argo. J. Geophys. Res. Oceans, 119, 15-29, https://doi.org/10.1002/2013JC009375.

Ren, L., and S. C. Riser, 2009: Seasonal salt budget in the northeast Pacific Ocean. J. Geophys. Res., 114, C12004, https://doi.org/ 10.1029/2009JC005307.

Rudels, B., L. G. Anderson, and E. P. Jones, 1996: Formation and evolution of the surface mixed layer and halocline of the Arctic Ocean. J. Geophys. Res., 101, 8807-8821, https:// doi.org/10.1029/96JC00143. 
Sato, K., T. Suga, and K. Hanawa, 2004: Barrier layer in the North Pacific subtropical gyre. Geophys. Res. Lett., 31, L05301, https://doi.org/10.1029/2003GL018590.

,-- and -2006 : Barrier layers in the subtropical gyres of the world's oceans. Geophys. Res. Lett., 33, L08603, https:// doi.org/10.1029/2005GL025631.

Sprintall, J., and M. J. McPhaden, 1994: Surface layer variations observed in multiyear time series measurements from the western equatorial Pacific. J. Geophys. Res., 99, 963-979, https://doi.org/10.1029/93JC02809.

— , and M. Tomczak, 1992: Evidence of the barrier layer in the surface layer of the tropics. J. Geophys. Res., 97, 7305-7316, https://doi.org/10.1029/92JC00407.

Takahashi, T., J. Olafsson, J. G. Goddard, D. W. Chipman, and S. C. Sutherland, 1993: Seasonal variation of $\mathrm{CO}_{2}$ and nutrients in the high-latitude surface oceans: A comparative study. Global Biogeochem. Cycles, 7, 843-878, https://doi.org/10.1029/93GB02263.

Talley, L. D., G. L. Pickard, W. J. Emery, and J. H. Swift, 2011: Descriptive Physical Oceanography: An Introduction. 6th ed. Academic Press, 555 pp.

Uda, M., 1963: Oceanography of the subarctic Pacific Ocean. J. Fish. Res. Board Can., 20, 119-179, https://doi.org/10.1139/f63-011.

Ueno, H., and I. Yasuda, 2000: Distribution and formation of the mesothermal structure (temperature inversions) in the North Pacific subarctic region. J. Geophys. Res., 105, 16 885-16898, https://doi.org/10.1029/2000JC900020.

—_, and - 2001: Warm and saline water transport to the North Pacific subarctic region: World Ocean Circulation Experiment and Subarctic Gyre Experiment data analysis. J. Geophys. Res., 106, 22 131-22 141, https://doi.org/10.1029/ $2000 \mathrm{JC} 000457$.

— and - 2003: Intermediate water circulation in the North Pacific subarctic and northern subtropical regions. J. Geophys. Res., 108, 3348, https://doi.org/10.1029/2002JC001372.
, and $\longrightarrow$ 2005: Temperature Inversions in the Subarctic North Pacific. J. Phys. Oceanogr., 35, 2444-2456, https:// doi.org/10.1175/JPO2829.1.

Vialard, J., and P. Delecluse, 1998a: An OGCM study for the TOGA decade. Part I: Role of salinity in the physics of the western Pacific fresh pool. J. Phys. Oceanogr., 28, 1071-1088, https:// doi.org/10.1175/1520-0485(1998)028<1071:AOSFTT>2.0.CO;2. - and — 1998b: An OGCM study for the TOGA decade. Part II: Barrier-layer formation and variability. J. Phys. Oceanogr., 28, 1089-1106, https://doi.org/10.1175/1520-0485(1998) 028<1089:AOSFTT>2.0.CO;2.

Wirts, A. E., and G. C. Johnson, 2005: Recent interannual upper ocean variability in the deep southeastern Bering Sea. J. Mar. Res., 63, 381-405, https://doi.org/10.1357/0022240053693725.

Xie, P., and P. A. Arkin, 1996: Analyses of global monthly precipitation using gauge observations, satellite estimates, and numerical model predictions. J. Climate, 9, 840-858, https://doi.org/10.1175/1520-0442(1996)009<0840: AOGMPU>2.0.CO;2.

— observations, satellite estimates and numerical model outputs. Bull. Amer. Meteor. Soc., 78, 2539-2558, https://doi.org/ 10.1175/1520-0477(1997)078<2539:GPAYMA >2.0.CO;2.

Yu, L. S., 2011: A global relationship between the ocean water cycle and near-surface salinity. J. Geophys. Res., 116, C10025, https://doi.org/10.1029/2010JC006937.

, and R. A. Weller, 2007: Objectively analyzed air-sea heat fluxes (OAFlux) for the global ocean. Bull. Amer. Meteor. Soc., 88, 527-539, https://doi.org/10.1175/BAMS-88-4-527.

, X. Jin, and R. Weller, 2008: Multidecade global flux datasets from the objectively analyzed air-sea fluxes (OAFlux) project: Latent and sensible heat fluxes, ocean evaporation, and related surface meteorological variables. OAFlux Project Tech. Rep. OA-2008-01, 64 pp. 